\title{
EL ENSUEÑO OCEÁNICO: LOS MERCADOS FINANCIEROS DE UNA PLAZA INTERREGIONAL EN ÉPOCA DE RECESIÓN (VALENCIA, 1480-1520)1
}

\section{The Oceanic Dream: The Financial Markets of an Interregional Place in Times of Recession (Valencia, 1480-1520)}

\section{Enrique CRUSELLES GÓMEZ}

Facultat de Geografia i Història. Universitat de València. enrique.cruselles@uv.es

Fecha de recepción: 11/09/2020

Fecha de aceptación: 20/10/2020

RESUMEN: A finales del siglo XV, Valencia manifestaba una crisis de crecimiento que se acentuaría en las décadas siguientes. De manera paradójica, era la época de total difusión de las prácticas comerciales adoptadas de los ambientes italianos un siglo antes. El análisis de los mercados financieros (seguros marítimos, arrendamientos de impuestos y crédito) muestra varias novedades socio-económicas respecto a tiempos pasados, manifestaciones del declive. Primero, relacionado con la promoción de los grandes linajes comerciales del pasado, el agotamiento de la reproducción social del grupo mercantil local, factor acentuado por la persecución inquisitorial de los hombres de negocios de ascendencia judeoconversa. Segundo, el desplazamiento de los comerciantes en algunos de esos mercados por las élites políticas urbanas que acaparaban los negocios financieros en beneficio propio y que recurrían a la intermediación de las empresas itálicas. Y finalmente la

1. Este trabajo se integra en el proyecto de investigación Desigualdad económica y movilidad social en la Europa medieval (siglos XIII-XVI), de la Generalitat Valenciana, prometeu 2019/072. 
participación empresarial de miembros enriquecidos del artesanado en la etapa de esplendor de la ciudad, que aprovecharon sus oportunidades con el desclasamiento del grupo mercantil.

Palabras clave: Mercaderes; comercio medieval; historia urbana, mercados financieros; dinámica social.

ABSTRACT: At the end of the 15th century, Valencia manifested a growth crisis that would accentuate in the following decades. Paradoxically, it was the time of total diffusion of the commercial practices adopted from the Italian environments a century before. The analysis of the financial markets (maritime insurance, tax leases and credit) demonstrate various socio-economic transformations with respect to past times, manifestations of decline. First, related to the promotion of the great commercial lineages of the past, the exhaustion of the social reproduction of the local mercantile group, a factor accentuated by the inquisitorial persecution of businessmen of Jewish converts descent. Second, the displacement of merchants in some of these markets by urban political elites who monopolized financial business for their own benefit and who resorted to the intermediation of italic companies. And, finally, the business participation of artisan members, enriched in the splendor stage of the city, who took advantage of their opportunities with the loss of social position of the mercantile group.

Keywords: Merchants; medieval commerce; urban history; financial markets; social dynamic.

Los negocios habían ido prosperando. Alcanzado el cambio de siglo, Onofre Ferrer mantenía contactos regulares con algunos de los destinos tradicionales del comercio valenciano, en especial con Cagliari y Palermo, mercados de consumo seculares de la pañería local. Y, con la prosperidad, había aplicado a la gestión de su empresa una teneduría de libros más desarrollada de lo que había sido habitual en los ambientes mercantiles de la capital valenciana. El libro mayor que ha sobrevivido al paso del tiempo abarca los años 1490 a 1510, la época de efervescencia de su actividad empresarial, y recoge un numeroso y variopinto agrupamiento de cuentas, entre las abiertas a clientes y corresponsales y las cuentas impersonales, dedicadas principalmente a la comercialización de tejidos y a la cobertura de riesgos de seguros marítimos. Es en esta última cuenta, que se prolonga a lo largo de todo el libro mayor, que el 15 de marzo de 1502 Ferrer anotó el cobro de una prima por la 
prestación de un servicio asegurador, un apunte escueto: «Més a 15 de dit al tresorer 10 ducats a 23 per cent de Portogal a Calicul. Rebut per lo dit. Déu la fasa salva». Las condiciones habían sido contratadas por Alfonso Sánchez, hombre de negocios, lugarteniente del tesorero real en el reino de Valencia e integrante de la camarilla de oficiales de ascendencia conversa puesta al servicio del monarca.

Es probable que el contrato cerrado por Sánchez salvaguardara alguna de las embarcaciones que componían las flotas de castigo enviadas en aquellos años por Portugal ${ }^{2}$, si bien la desaparición de los libros de seguros del notario Joan Casanova no permiten aclarar la duda. Asimismo, parece probable que otro seguro marítimo cerrado por el operador florentino Bernardo da Rabatta (Igual, 2018: 242) el 18 de abril, sobre una nave que surcaba las aguas en esos momentos hacia aquel puerto indio («exida a Calicult») y cubierto por Ferrer con poco más de ocho ducados, tuviera una finalidad similar. Durante el año siguiente, otros comerciantes contrataron pólizas para cubrir los riesgos del viaje a las nuevas colonias portuguesas en el océano Índico: los asegurados fueron el genovés Benedetto Pinello, aquel mismo operador toscano o nuevamente el propio tesorero (Cruselles, 2007: 295, 298, 309, $329,332$ y 368$)^{3}$. Pero también, en esos días, Ferrer corrió con los riesgos de navíos que cruzaban el Atlántico con destino a las Antillas, sin especificar puerto. Eran operadores comerciales interregionales como el genovés Francesco Palomar y locales como Jaume Marga, o el mismo oficial real, los que buscaban aseguradores para esos barcos que atravesaban el océano con destino al Nuevo Mundo y por los que cobraban primas entre el 16 y el 18 por ciento (Cruselles, 2007: 319 y 320).

La actividad de Onofre Ferrer en este mercado financiero, nacido un siglo atrás, había despuntado hacia el cambio de centuria. Siguiendo los apuntes de su libro de cuentas, en 1500 aseguró mercancías y naves en una cuarentena de ocasiones; en 1502, el año con el que hemos comenzado esta descripción, alcanzó las doscientas. Además, Jaume Salvador era el escribano público que en aquella época concentraba

2. En los primeros meses de aquel año el reino luso armaba una copiosa flota para tratar de consolidar los éxitos alcanzados por Vasco de Gama pocos años antes. Tras zarpar con una escuadra de menor envergadura en el verano de 1497 y alcanzar Calicut después de casi un año de navegación, el marino había regresado a Lisboa al cabo de dos años, en el verano de 1499, con las promesas de riquezas inagotables. En esa segunda ocasión, a principios de febrero de 1502, Vasco de Gama capitaneaba una flota de diez naves, acompañado por una flotilla de apoyo integrada por otras cinco bajo el mando de Vicente Sodré, para afianzar militarmente la ruta del Cabo, amenazada por las hostilidades india y árabe sufridas por Pedro Álvares Cabral. Y tras ellos, en torno al inicio del abril siguiente, zarparon cinco embarcaciones más capitaneadas por Estêvão da Gama (Spallanzani, 1997: 24 y 71).

3. A pesar de que la base de operaciones de la ruta del Cabo se había trasladado a Cochín, más al sur, ante la hostilidad de la población de la ciudad de las especias, los seguros marítimos seguían haciendo referencia a esta última, señal evidente de que la información sobre los nuevos hallazgos occidentales no se difundía con la misma celeridad por todo el continente. 
buena parte del registro notarial de ese mercado: si en 1500 su mesa intervino en el $70 \%$ de los contratos asumidos por Ferrer; en 1502, esa representación subió al 75\% (Cruselles, 2007: 264-269 y 291-318) ${ }^{4}$. Por ello, vale la pena acercarse a la realidad de este mercado financiero más innovador a través de la actividad de aquel notario predominante, en el año más próximo a la expedición portuguesa.

En 1499 la mesa de Jaume Salvador registró, al margen del protocolo y el notal habituales, un libro de seguros marítimos que contenía 321 contratos, algunos de los cuales no afectaban a viajes marítimos ${ }^{5}$. En ningún momento participó Onofre Ferrer, extrañamiento que también confirma la ausencia de referencias en su libro de cuentas. A lo largo de diez meses pasaron por la mesa notarial de Salvador 175 operadores para asumir algún riesgo, superando en número los valencianos (128) a los extranjeros (35) y al resto de agentes catalano-aragoneses $(10)^{6}$. Con estos datos puede intuirse que la actividad aseguradora, con su estrategia especulativa aplicada más allá del caso habitual del transporte marítimo de mercancías (por ejemplo, una apuesta sobre el fallecimiento de un personaje político del momento o el desenlace de un acontecimiento bélico), se había difundido ampliamente por todos los niveles de la sociedad ${ }^{7}$ o, en otros términos, había dejado de ser un negocio exclusivo de comerciantes.

4. El otro notario que registraba la parte menor de los contratos era Joan Casanova. Solo en una ocasión Ferrer fue a una escribanía distinta, la de Mateu Gil.

5. El volumen notarial ha perdido los cuadernos correspondientes a los meses de noviembre y diciembre (Archivo del Reino de Valencia -en adelante ARV-, Protocolos, n. ${ }^{\circ} 2699$ ).

6. Reconstruido esencialmente también a partir de la información proporcionada por un solo notario, el mercado surgido a lo largo de las primeras décadas del siglo XV arroja una imagen bien distinta: 105 operadores mercantiles extranjeros aseguraron en 510 ocasiones, frente a 78 hombres de negocios locales, que lo hicieron en 426. Entre los primeros destacaron el lombardo Filippo da Casate, con 120 seguros, y el florentino Gherardo di Giovanni Gianfigliazzi, con 73, representación parcial de una presencia más continua si atendemos a la cantidad de años que vivió como factor en la plaza valenciana (Mainoni, 1982: 71; Cruselles, 2006: 624-625; Piffanelli, 2014).

7. Un ejemplo extremo evidencia la difusión de la técnica aseguradora en la sociedad valenciana de la época. Cuando a mediados de septiembre de 1499, el mercader Jaume Puig acudió a la mesa de Salvador para escriturar un seguro que cubriera los riesgos del transporte marítimo de un cargamento de trigo importado desde Málaga, él mismo propuso una cobertura de cien ducados en representación de «les monges de Iherusalem», además de los cien que ponía por cuenta propia. Esta pequeña orden de religiosas terciarias franciscanas, fundada en Barcelona a mediados de siglo, había conseguido fundirse unos años antes de este contrato notarial con las monjas clarisas del convento de la Trinidad de Valencia. Es probable que la estrategia especulativa que hay tras la propuesta financiera supusiera una evaluación de riesgos aceptable, quizá menores a los contraídos con la adquisición de un censal, crédito de duración temporal superior al viaje malagueño cuya inmovilización del capital proporcionaba mayores intereses, pues la prima del seguro era del $3 \%$ mientras que la tasa de interés del censal seguía rondando en esta época el 6\%, el doble. En cualquier caso, las monjas debían contar con la intermediación 
La difusión local de la actividad del mercado de seguros marítimos se aprecia asimismo en el perfil social de los asegurados. Del total de operaciones, ciudadanos y nobles valencianos contrataron coberturas de riesgos en el $70 \%$ de los casos, mientras que operadores catalano-aragoneses se limitaron al 10\% y los extranjeros, al 20\%. Los rasgos de este mercado financiero habían cambiado desde la época de su constitución ${ }^{8}$ : si bien es cierto que algunos corresponsales, factores u operadores afincados permanentemente en Valencia desarrollaban en este mercado una parte de sus estrategias de gestión de los riesgos marítimos, incluso para viajes que no tenían que ver con la actividad portuaria de la ciudad, el reducido número de operaciones evidencia que las grandes empresas internacionales operaban desde otros grandes mercados o concertaban sus pólizas en sus ciudades de origen. En Valencia, solo es reseñable casos como los de los sieneses Burgarini y Spannochi o de los florentinos Barzi y Rabatta, que bajo comisión contrataban seguros en unas pocas ocasiones a lo largo del año? Al contrario, la intervención genovesa era escasa, superada claramente

de un operador mercantil, en este caso Puig, seguramente conocido, que era al mismo tiempo el comerciante que importaba el grano, por tanto, ducho en los riesgos del transporte marítimo. Eso sí, de entre el casi medio centenar de personas que aseguraron este cargamento, por un valor total cercano a los 1700 ducados, las monjas asumieron el riesgo más alto, por encima de los Spannochi, Boixol, Macip, Monfort o Monet, comerciantes acostumbrados a arriesgar en este mercado cifras más elevadas.

8. Sin poder hacer una comparación completamente fiable por motivos heurísticos, al menos se evidencia que muchas décadas antes, aunque la demanda interna sustentaba en mayor medida la actividad del mercado, algunas rutas internacionales dependían de la actividad de los operadores itálicos, principalmente toscanos y lombardos. Los seguros contratados para el transporte de lana hacia las ciudades del norte de la península itálica dependían en un $80 \%$ aproximadamente de la demanda exterior; los del transporte de excedentes agropecuarios hacia Flandes, en un 30\%; y los de la navegación en el Mediterráneo oriental, tanto en una época como en otra, obedecían a los negocios de los operadores internacionales. Este repliegue del capital mercantil extranjero del mercado asegurador local se aprecia también en Barcelona en su etapa de recesión (Cruselles, 2006: 629 y 634-635).

9. Si bien el sienés Battista Burgarini demostraba un comportamiento mercantil parecido al de los comerciantes locales, algunos de los seguros contratados por él alcanzaban cifras más elevadas, como los 633 ducados que cubrían el transporte de paños y cordellates a Palermo. En otra ocasión, enviaba azúcar y lana de Valencia a Porto Ercole con una cobertura de 250 ducados y, más tarde, como comisionado de la compañía Boninsegna, aseguraba el transporte de azúcar entre Cádiz y Talamone. Bernardo da Rabatta, con una comisión indirecta de la compañía Ruccellai de Roma, hacía asegurar en dos ocasiones alumbre cargado por representantes de la Cámara Apostólica entre Civitavecchia y Flandes e Inglaterra; con otra de Giuliano del Giocondo, mandó asegurar cueros irlandeses exportado desde Galway a los puertos ligures y toscanos; y en su calidad de procurador de la compañía Del Nero enviaba azúcar refinado a Civitavecchia. Cesare di Barzi solía contratar como comisionado de otros florentinos afincados en Lisboa, Bartolomeo Marchionni o Leonardo Nardi, protagonistas financieros de la expansión oceánica portuguesa (Guidi Bruscoli, 2018). En junio negociaba el aseguramiento de un cargamento de azúcar estibado por el factor del rey de Portugal transportado desde Madeira 
por la actividad de los corresponsales franceses o alemanes. En cualquier caso, como se ha mencionado, el grueso de la actividad de este mercado estaba en manos de agentes locales y es en este grupo donde queremos centrarnos. A grandes rasgos, la demanda valenciana de seguros se distribuye en tres grupos: los comerciantes, el colectivo heterogéneo de artesanos-tenderos y el lugarteniente del tesorero real mencionado al principio de este trabajo. Si los primeros concentraban algo menos del $50 \%$ de la demanda de coberturas, los otros dos oscilaban en torno al $25 \%$, lo cual implica que el oficial-mercader-doncel de origen converso demostraba una actividad similar a la de toda la comunidad de tenderos, maestros artesanos y marinos de la ciudad, evidenciando la envergadura empresarial de ese grupo ${ }^{10}$.

Pero, dejando al margen el caso del tesorero real, cuya relación privilegiada con el monarca lo llevaría a disfrutar en los años siguientes de una posición de preponderancia en el mundo mercantil valenciano nunca disfrutada por otro operador local (Díaz, 1992; Salvador, 2008), queremos resaltar el otro aspecto surgido de este análisis: los ambientes artesanales y de intermediarios locales representaban la mitad de la contratación de los supuestos sectores mercantiles internacionales valencianos. Ciertamente, en general, los contratos negociados con artesanos y tenderos afectaban a un volumen reducido de mercancías destinadas a la satisfacción del consumo interno del mercado capitalino o la comercialización de su producción textil. Sin embargo, un siglo antes, los artesanos y tenderos prácticamente no participaban en

a Civitavecchia con una cobertura de 2500 ducados; en agosto, cubría los riesgos de artículos textiles importados de Bretaña a Lisboa; y en octubre volvía a intervenir en representación de los factores del monarca portugués, asegurando por 2630 ducados el envío de azúcar desde Madeira a Venecia. Entre los pocos contratos de genoveses, Francesco Palomar aseguró el transporte de azúcar desde Lanzarote o «Sant Bonaventura» hasta Cádiz (1499, mayo 4, junio 17, julio 6 y 8, agosto 8, 16, 21 y 26, y septiembre 16. ARV, Protocolos, n. ${ }^{\circ} 2699$ ).

10. Alfonso Sánchez había levantado una empresa mercantil integrada en una amplia red internacional de colaboradores para los que actuaba como corresponsal y para los que ponía a su disposición el mercado valenciano. En bastantes ocasiones, concertaba contratos de seguros que probablemente no afectaban a negocios personales. Podría ser el caso de un tráfico que combinaba la expedición de vinos y otras mercancías no mencionadas entre Andalucía e Irlanda, los salmones y cueros importados desde la isla hasta Cádiz y, de allí, los cueros enviados a Savona, Livorno o Talamone, y los salmones a Civitavecchia o el puerto fluvial de Ripa Grande en Roma. Otro contrato lo cerraba casi a mediados de junio para el trasporte de hierro «e ferragte» desde Vizcaya a Mesina, siguiendo una ruta que agregaba buena parte de los puertos de la península ibérica, Cagliari, Civitavecchia y Palermo. Recorridos distintos tenían los aseguramientos de una carga de azúcar enviada desde Gran Canarias a Aigües Mortes o Marsella, a mediados de julio, o de 600 barriles de tonina, entre grandes y pequeños, estimados en 2300 ducados, estibados en Lagos, en el Algarve, y transportados hasta Ripa Grande, unos días más tarde, repitiendo un trayecto similar al asegurado hacia finales de junio, este de menor valor, por 1200 ducados. Según recoge otro contrato de principios de octubre, parece que en Lagos operaba su hermano Juan Sánchez (1499, marzo 39, junio 12 y 25, julio 15 y 18, y octubre 7. Ibidem). 
el mercado de seguros marítimos, dependiente de la intermediación exclusiva de los operadores interregionales.

De la misma manera, el análisis del perfil de los aseguradores valencianos, aquellas 128 personas antes citadas, aporta una reflexión similar. Esos agentes, que acumulaban el $87,5 \%$ de las coberturas de riesgo escrituradas por Salvador en ese año, contra el $10 \%$ asumido por los operadores extranjeros, se repartían de manera desigual: junto a 40 comerciantes que aportaban una parte significativa del servicio del mercado (1658 coberturas), trabajaron 29 comerciantes que demostraron una presencia incidental (126 ocasiones), 17 mercaderes conversos (463), aún no perseguidos por la Inquisición, y 42 artesanos-tenderos (1151 coberturas). Es decir, comparativamente, el mercado financiero de seguros marítimos dependía de la estrategia de riesgo de una proporción doble de comerciantes frente a artesanos, destacando la primacía matizada de los primeros por cuanto una parte significativa del grupo comercial carecía de entidad o sería extinguida en un plazo de tiempo breve ${ }^{11}$. Desde el punto de vista de la actividad, a pesar de la evidente superioridad financiera de los comerciantes, se derivaba una relativa homologación en el comportamiento empresarial. Por orden de mayores coberturas, el listado de los principales aseguradores valencianos sería el siguiente: el mercader Lluís Monrós (109), el converso Joan Macip (103), el carpintero Bertomeu Monfort (99), el comerciante Pere Vidavia (89), el converso Jaume Macip (87), el comerciante Benet Boixol (84), el pañero Jaume Pérez (84), el mercader Ausiàs Lleonard (82) y el pelaire Antoni Aguiló (80). Les siguen, con unas 70 operaciones anuales, los comerciantes Jaume Ballester, Gaspar Goçalbo, Pere Espina, Miquel Alcanyís o Joan Miquel.

Esta docena de mayores operadores del mercado refleja bien la heterogeneidad de la oferta financiera local. En la parte alta de la escala empresarial, comerciantes, en principio habituados a la actividad marítima ${ }^{12}$, que tenían una presencia social moderada: ninguno de ellos es mencionado en una crónica local por la ostentación

11. Estos datos vuelven a sugerir la comparación con el mercado financiero de la primera mitad del siglo XV: casi todos los aseguradores valencianos que participaron entonces pertenecían al grupo mercantil. En aquella época el maestro artesano era mantenido fuera de las posibilidades especulativas de estos negocios, reservados para mercaderes.

12. De tratar de hacer, con el escaso nivel de investigaciones, un censo de los mercaderes locales más activos en estas décadas finales del siglo XV, debería incluirse seguro a: Joan Abelló, Miquel Alcanyís, Benet Boixol, Pere Cavallo, Joan Escolano, Joan Espina, Pere Espina, Lluís Garcia, Pere Garcia, Jeroni Gual, Jaume Macip, Joan Macip, Jaume Marga, Joan Miquel, Lluís Monrós, Guillem Navarro, Onofre Pellaia, Domènec Perandreu, Gaspar Rull, Miquel Salvador, Alfonso Sánchez y Pere Simó. A pesar de la evidente proximidad entre los negocios asegurador y mercantil, solo los resaltados en cursiva (la mitad de la nómina) demostraban interés por el mercado asegurador, habiendo otros hombres de negocios que, a pesar de su febril actividad comercial interregional, como Pellaia, Perandreu o Sánchez, participaron de manera más episódica en el mercado de seguros marítimos. 
de cargo político alguno, ni de gestión técnica como era el caso de los clavarios municipales, ni de representación más honorífica como era el de administrador de hospital (Carreres, 1935) ${ }^{13}$. En medio, un grupo de comerciantes de ascendencia conversa que ya había observado con horror cómo amigos y compañeros suyos habían sido procesados y condenados por la Inquisición, destino sombrío que algunos de ellos aún tendrían que recorrer ${ }^{14}$. Finalmente, un heterogéneo grupo de pañeros, pelaires, tintoreros, apuntadores de paños, pasamaneros, corredores de comercio o carniceros, por citar algunas profesiones, entre las que destacaban por su número los tenderos (10 personas) y el artesanado del textil (18). Un grupo con un perfil social interesante por cuanto el notario los trataba indistintamente un día como artesanos o tenderos como al día siguiente los denominaba mercaderes ${ }^{15}$. Lo cual indica que, aun siendo el mercado local el ámbito preferente de su actividad profesional, por cuanto no eran hombres de negocios que frecuentaran los mercados extranjeros, les era reconocido un cierto prestigio, tanto económico como social ${ }^{16}$.

13. Lo cual hace sospechar un desclasamiento general del grupo mercantil. Podemos plantearlo desde otro punto de vista: la inversión patrimonial en bienes dotales y el recurso al matrimonio como mecanismo de construcción de redes de sociabilidad. Comparada la cuantía de los bienes dotales de finales del siglo XV, se ha constatado que en el grupo artesanal se daba una extrema variabilidad (entre 5 a 500 libras), tanto como en el grupo mercantil (entre 40 y 600), situando respectivamente las medias en 80 y 195 libras valencianas. Por encima de esta penúltima cifra, se hallaban hasta el $82,6 \%$ de las dotes entregadas por mercaderes, si bien solo un $43,5 \%$ de ellos superaba la media obtenida en su grupo. Además, el 14\% de los artesanos recibían dotes superiores a las 125 libras. Todo ello implica que, desde un punto de vista de la constitución patrimonial, un amplio sector del grupo mercantil estaba en la misma posición social que la élite del grupo artesanal. También llama la atención la similitud del porcentaje $(35 \%)$ en la elección de esposo por las hijas de los comerciantes entre mercaderes y artesanos (Cruselles, 1996: 1372, 1375 y 1379-1380).

14. La nómina de mercaderes conversos que aseguraron barcos y mercancías en 1499 está compuesta por Gabriel Andreu, Jaume, Joan y Pere Macip, Jaume y Lluís March, Dionís Moncada, Àngel, Pau, Pere y Pere Ramon Pardo, Gil Roís, Lleonard y Martí Santàngel, Joan Saragossà y Lluís Vives, padre e hijo. De estas diecisiete personas, al menos diez se presentaron ante el tribunal, sufriendo una sentencia dura la mitad de ellas.

15. En este sentido, la documentación ofrece la sensación de que la distancia social entre las profesiones mercantil y aquellas limitadas al mercado local (tendero, artesano) era más amplia en la etapa inicial de despegue de la economía urbana valenciana. Además, con dos rasgos distintivos de su trayectoria social: dar el salto de grupo socio-profesional implicaba la acumulación de riqueza durante más tiempo y una vez alcanzada la nueva profesión no se compaginaba con la anterior (Cruselles, 2001: 76-87). Más extraños son aún para esa época temprana los casos de preservación de la profesión artesanal, a pesar de manifestar una febril actividad en los mercados exteriores o de disfrutar de una holgada posición económica, cuando se aseguraba el ascenso social de los descendientes a la aristocracia urbana (Rodrigo, 2013; Aparici, 2018).

16. Si atendemos a las denominaciones profesionales, podría considerarse que, a finales de siglo, bastantes de estos maestros artesanos no eran solo eso, unos artesanos socialmente inferiores a los prestigiosos hombres de negocios locales, una diferenciación un tanto rígida para 
Aunque también se puede plantear una argumentación distinta: el desclasamiento social de la profesión mercantil, materializado en la contracción de la diversidad de actividades y en el apartamiento del ejercicio tradicional de cargos públicos apropiados, rasgos singulares de los grandes hombres de negocios de la época del despegue mercantil de Valencia, permitía a estos tenderos y maestros artesanos adjudicarse el perfil profesional de un grupo en recesión social ${ }^{17}$.

Esta trayectoria descendente del grupo era consecuencia, en parte, de la propia promoción social experimentada por los grandes linajes mercantiles de principios del siglo XV que desproveyó al grupo de sus elementos más conspicuos. Enriquecidos con sus múltiples negocios, redirigidos parte de los capitales acumulados hacia la adquisición de propiedades inmuebles rurales y urbanas, centrados en el desempeño de cargos de gestión pública, que progresivamente irían sustituyendo por magistraturas municipales y regnícolas de mayor relevancia política, los hombres de negocios más conocidos desaparecieron hacia mediados del siglo XV. Primero, como consecuencia de la renovación demográfica natural ${ }^{18}$, pero sobre todo derivado de la

esta época. Al contrario, disfrutaban de una consideración social parecida: a Antoni Aguiló se le cita como pelaire y como mercader; Joan Almenara, «botiguer», «droguer» y mercader; Miquel Bernabeu, carnicero y mercader; Marc Castrellenes, «argenter» y mercader; Martí Enyego, tendero y mercader; Simó Ferrer, tintorero y mercader; Baltasar Forés, tendero y mercader; Pere Gil, «botiguer», «draper» y mercader; Joan Navarro, «formatger» y mercader; o Joan de Vitoria, sastre y mercader. Ciertamente, otros mantuvieron solo su perfil artesanal. No sabemos bien el significado social y económico que implica, pues puede evidenciar tanto el prestigio de la adopción del perfil profesional mercantil como, seguro, la participación de los artesanos en la actividad mercantil. De hecho, el artesano que más veces asumió coberturas de riesgo fue Bertomeu Monfort, que siempre fue designado por el notario como «fuster» en ese año, 1499.

17. Aunque el término sea ambiguo por cuanto se considera que no se debe generalizar el comportamiento empresarial de la élite de hombres de negocios italianos a los mercaderes locales para acabar generalizándolo a una escala de pequeños, medianos y grandes hombres de negocios, que permite integrar el dinamismo de los maestros artesanos de ciertas corporaciones, se asume que la concentración de negocios empresariales en el tránsito a la Modernidad provocó la pérdida de peso de artesanos, pequeños mercaderes y operadores esporádicos de los grandes circuitos comerciales (Iradiel, 2017a: 192 y 204-205).

18. Hacia 1434 fallecía Guillem Rana, mercader de origen lombardo. En los años siguientes, perecerían Jaume Esteve de Llimotges, Gabriel Cabanyelles, Pere Tarroja, Antoni Ros o Francec Pellicer. Pere Dauder vio el final de sus días a principios de la década de 1440, como Ramon de Puig-roi, Antoni Garriga o Bernat Penya-roja. Tampoco tardaría en morir Joan Mainés. Una crónica local recuerda el asesinato del mercader de origen mallorquín Daniel Pardo y la brutal ejecución en 1445 de su asesino, Vidal Riusec (Sanchis, 2001: 185). Joan Alegre, en su juventud pañero, después uno de los grandes inversores en el mercado de valores, falleció en 1447. A finales de ese año morían también Pere Dezcortell y Daniel Cornet y, años más tarde, en 1454, su hermano Francesc. En 1448, abandonaba este mundo Jaume Balaguer y, en 1449, lo hacía Mateu Corona. En la década de 1450 también habían perecido Bernat Sallit, Joan Amalrich, Bernat Guillem de Reig, el principal inversor valenciano en el mercado de seguros marítimos de la época precedente, Vicent Corts, Bonanat Blanch, Joan d'Eixarch o Pere Llorach y, en la 
carencia de reemplazo, resultado de la promoción social familiar. Cuando llegaron al final de sus días, muchos de ellos disfrutaban ya de la condición de «ciutadans honrats», e incluso algunos, como Jaume Perfeta, habían alcanzado los escalafones de la baja nobleza urbana. Paralelamente, los negocios se iban abandonando. Pero, sobre todo, la cuestión residía en que sus descendientes continuaron con sus actividades inversoras y especuladoras, abandonando los negocios mercantiles que no dependían directamente de las instituciones políticas, mientras hacían ascender la familia hasta aquellos deseados peldaños de la prohombría. Ya todos eran ciudadanos y donceles, se entregaban de lleno al desempeño de cargos políticos e invertían en la compra de títulos de créditos privados e institucionales y en la acumulación de nuevas propiedades dignas del recién alcanzado estatus. Con aquel cambio, habían vuelto la espalda al mar y sus descendientes estaban destinados a otros horizontes sociales ${ }^{19}$. Esgrima, equitación, danza, educación latina, escuderos y maestros..., las preocupaciones de los hijos y nietos de aquellos enriquecidos mercaderes se concentraban en guardar la necesaria imagen de opulencia social, vinculada al disfrute de privilegios de la renovada élite social.

La trayectoria social ascendente de estos renombrados linajes de comerciantes, que los llevaría al abandono de la profesión en su integración con las élites políticas locales, se combinó con el desclasamiento del resto del grupo mercantil, privado de las oportunidades empresariales y del ejercicio de cargos político-administrativos que habían disfrutado sus compañeros de profesión. Aunque había un grupo que, de manera natural, podría haber jugado un papel esencial en la renovación secular del grupo mercantil. Se trata del dinámico colectivo de comerciantes de ascendencia conversa que, desde las primeras décadas del siglo XV, había acumulado riqueza a lo largo de su proceso de integración, ralentizado por los recelos sobre su pasado religioso. Al menos una treintena de familias y ramas familiares se codeaban con

siguiente, lo hicieron Joan Sallit, Joan Amat, Daniel Barceló, mucho después de que feneciera su hermano Francesc, Pere d'Amiga, Miquel de les Velles, Vicent Granulles, Jaume Perfeta o Jaume Bertran. Esa misma crónica local recuerda que, en 1464, sucumbieron, entre otros comerciantes que «en parença dels gents fien grans fahenes, e.ls tenien per afeats», Llorens Soler, uno de los hombres de negocios más activos del mercado de cambios de la primera mitad de siglo, Francesc Colomer y su hijo, Francesc Comes y el suyo, y Miquel d'Eivissa, «lo pus afeat cambiador qui sia estat en nostre temps» (Sanchis, 2001: 284).

19. En 1478, los tutores del joven Perot, nieto de ocho años del mercader Bernat Penyaroja, fallecido más de tres décadas antes, solicitaban al Justicia Civil el permiso para contratar un maestro «qui aquell guarde anant, stant e tornant de les scoles, hoc encara quill porte-li... a scola de dançar e de esgrima per ésser púbil opulent e rich». Unos años antes, el oficial municipal aprobaba la manutención del nieto de Joan Alegre, fallecido en 1447, que «attentis patrimonio et condicione e statu dicti minoris et eius patris contemplaba aliments per a ell e hun scuder, hun moço, hun rocí e una mula» (1478, diciembre (14). ARV, Justicia Civil, n. ${ }^{\circ}$ 929, m. 18, f. 11; y 1471, octubre 3. Ibidem, n. ${ }^{\circ}$ 923, m. 14, f. 22). 
lo más granado del grupo profesional, en una época en que la herencia religiosa carecía de tanta relevancia social: Martí y Gabriel Andreu, los descendientes del corredor Rossell Bellpuig, en especial Bonanat, fallecido en la medianía de la centuria, los Belluga, cambistas, los Bellviure, Lluís Conca, Galceran Martí, de origen mallorquín, como los Pardos, mercaderes y banqueros, Vidal Riusec, Joan Salvador, Daniel Sánchez, Martí Roís, sus parientes, y los Santàngel, todos ellos aragoneses, los Valldaura, los Valleriola o los Vives. Cada una de estas familias, generación tras generación, se dedicó a la acumulación de una fortuna generada con las actividades mercantil y financiera, dinero que no podía transformar en capital social. Conforme los hijos de sus compañeros de profesión cristiano-viejos se iban retirando de los negocios, estas familias de operadores de ascendencia conversa iban ampliando sus negocios, hasta cobrar un peso financiero notorio en la década de 1470. Sin embargo, su ascenso social, aún tímido, se vio truncado a partir de la década siguiente, cuando los tribunales inquisitoriales mantuvieron con celo su actividad persecutoria. El destino de la familia de banqueros Roís puede ser un buen exponente de este fracaso social, derribada cuando había forzado las puertas de la nobleza baja, sin haber abandonado los negocios (Cruselles, 2019), aunque es un caso más entre el elevado número de hostigados en las filas mercantiles ${ }^{20}$. Su ejemplo demuestra que estos hombres de negocios, plenamente integrados en la élite dirigente, ya entrada la segunda mitad del siglo XV, disfrutaban de una envergadura empresarial relativamente importante. Ciertamente, no todos habían alcanzado la posición de los Roís ni habían levantado una empresa de su relevancia. En cualquier caso, las reconciliaciones reiterativas que sangraban financieramente al colectivo y las composiciones ofrecidas por el monarca que los dejaba exhaustos, los procesos con penas graves e infamantes, que les prohibía llevar ropas lujosas e incluso imponía

20. Entre los perseguidos figuran: Gonçal, Anton y Alfons Roís, Bernat, Pere, Ferrer y Joan Macip, Bernat y Ausiàs Pintor, banqueros, Damià y Dionís Rossell, Lluís y Dionís Moncada, Ferrer Domènec, Gabriel Dauder, Joan y Jaume Sànchez, Lleonard Serra, Pere Pertusa, Pere Besant, Anton Esteve, Benet Pròixita y Baltasar Valleriola, cambistas, Miquel Ferrer, Ferran d'Aguilar, Daniel, Gelabert y Joan Valleriola, Daniel, Gabriel y Manuel Çabata, Daniel y Gaspar Bellviure, Francesc, Joan y Galceran Salvador, cambista, Ferran Fuster, Gil y Martí Roís, Gisbert Tolosa, Gabriel Tagamanent, Gabriel y Lluís Palau, Guerau Llopis, Gabriel, Joan, Lluís y Ramon March, Galceran Adret, Guerau y Galceran Llopis, Gisbert de Santa Fe, Jaume Baró, Joan Monrós, Joan y Rafael Despuig, Jofré Riusec, Jofré de les Escales, cambista, Joan Torí, Manuel, Joan y Pere Arenós, Joan Ferrer, Galceran, Lluís y Pere Nadal, Lluís Sanç, Joan, Lluís y Pere Solanes, Nicolau Valldaura, Lluís Vives, padre e hijo, Pau y Manuel Vives, Pere Guasch, Pere Baró, Pere del Mas y Pere Pertusa, Alfons Ferrandis, cambista, Bernat Blanch, Francesc d'Artés, cambista, Lluís Bertran, Gabriel, Marc y Joan Pelegrí, Jaume Monrós, Joan Belluga jr., cambista, Joan de València, Joan Fenollosa, Jaume, Lleonard y Pere Sànchez, Pere Guimerà, Tomàs Francesc, Gabriel Rojals, Manuel y Francesc Esparça, Joan y Lluís Roig, Ramon Pardo y Guillem Castellar. 
hábitos y sambenitos vergonzantes, los embargos de bienes patrimoniales y dotales, la exhumación de antepasados, la prohibición de abandonar la ciudad y el castigo a los huidos determinó el desclasamiento de todo el colectivo y su ruina. No lo sabemos con certeza aún, pero pocos de los más significados debieron escapar a la persecución. Y con su hundimiento, aquella facción que en buena medida podría haber participado en la reproducción social del grupo mercantil fue prácticamente exterminada, si casi literalmente no, sí desde la perspectiva de una muerte social. Dejaron de contar y en la renovación del grupo mercantil solo pudo participar una porción reducida de comerciantes cristiano-viejos, abriéndose las puertas del ascenso social a un amplio grupo de representantes de los colectivos artesanales.

La larga etapa de crecimiento de la economía mercantil valenciana llevó la capital del reino a convertirse en una metrópoli económica caracterizada por la consolidación de sus mercados financieros donde operaban, a pesar de las cambiantes coyunturas políticas, diferentes colectivos de operadores extranjeros, por la integración regional y la extensión de la superioridad económica de la capital sobre su reino, incluso más allá de sus fronteras políticas, y por la consolidación de un sector empresarial autóctono animado por el rápido enriquecimiento y la inmigración transregional. Ciertamente, este crecimiento tuvo sus limitaciones y condicionantes de manera tal que Valencia fue siempre un centro de segundo orden en el ámbito continental, pero aun así supuso la difusión de un conocimiento práctico empresarial y la adopción de una legislación mercantil que facilitó la actividad de los operadores foráneos. Llegados los años finales de la centuria, el despegue comercial valenciano comenzó a evidenciar signos de recesión y su organización económica fue demostrando desequilibrios cada vez mas pronunciados ${ }^{21}$.

Desde mediados de siglo, el repliegue de las élites mercantiles llevó parejo la relegación del resto del grupo mercantil de las prebendas y beneficios que el sistema económico urbano había procurado en la etapa de despegue a los predecesores que habían terminado abandonando la profesión mercantil. En parte porque, al tiempo que los sistemas financieros institucionales se aproximaban al colapso, la nobleza urbana y la ciudadanía desalojaron a los comerciantes de las posiciones de favor que las instituciones les habían reservado hasta entonces. Fijémonos con mayor detenimiento en los mercados de renta pública y en el sistema de arrendamiento de impuestos, antiguos mercados de valores de destinos siempre entrelazados ${ }^{22}$.

21. Por ejemplo, los indicios documentales apuntan a la creciente dependencia del sistema comercial del capital mercantil exterior, al tiempo que se reducía la presencia interregional de operadores locales, y a la superioridad, según demuestra la fiscalidad aduanera, de la actividad portuaria de Barcelona sobre Valencia (Iradiel, 2017b: 388; Igual, 2019: 80 y 83).

22. En el caso del mercado de deuda pública, es suficiente con hacer una breve comparación entre dos años, 1435 y 1495, del pago de los intereses de este negocio propiamente ciudadano. Si los porcentajes de inversores ciudadanos y de profesionales liberales no experimentaron casi 
Mientras la deuda pública municipal había seguido creciendo a lo largo de la segunda mitad de la centuria, al calor de los préstamos realizados por la ciudad a los sucesivos monarcas, la deuda de la Diputación del General se enquistó. En otros términos, en una institución antes y en la otra más tarde, dependiendo de su capacidad de forzar la presión fiscal sobre la población, los ingresos procedentes de los impuestos indirectos solo servían para cubrir los intereses de la deuda consolidada. Con la confirmación de esta tendencia, se produjo el ataque de la élite política contra los mercaderes, responsabilizados de la inoperancia del sistema y de la búsqueda de un beneficio particular que perjudicaba a los titulares de deuda por cuanto acordaban precios bajos para los arrendamientos de la recaudación de impuestos. En la Diputación del General, la disputa entre el grupo representante de los censalistas y algunos nobles que querían aventurarse en esos negocios financieros estalló hacia mediados de siglo ${ }^{23}$. Tras un lapso de tiempo en que la recaudación de impuestos no fue arrendada, hacia el arranque de la década de 1470 la nobleza, compradora de la deuda pública, controló los arrendamientos de los impuestos y los gestionó directamente ${ }^{24}$. En el municipio, la reacción llegaría unos años más tarde, con un

cambio a lo largo de ese periodo (sobre el $21 \%$ en el primer caso; entre el 15 y $12 \%$ en el del segundo), donde sí se demuestran variaciones significativas es en los extremos de la escala social. La nobleza pasó a acaparar del 28 al casi el 50\% de la presencia, cuando más de doscientos representantes del grupo invirtieron en deuda municipal. Por el contrario, mercaderes y artesanos redujeron sus compras: los primeros a la mitad, pasando del $13 \%$ al $6 \%$; los segundos, casi a la desaparición, del 9,5 al 1,5\%. La compra de deuda municipal se había convertido a finales de siglo en un negocio de élite. En el otro caso, la deuda del General estaba copada por esa élite política desde época mucho más temprana (Archivo Municipal de Valencia -en adelante AMV-, Claveria de Censals, N-17 y N-55).

23. Desde el arrendamiento de 1450 , se abrió un conflicto encarnizado por parte de los dirigentes políticos contra el continuador de la época de la supremacía mercantil, Vicent Alegre, ciudadano hijo del mercader Joan Alegre, fallecido pocos años antes, secundado por un grupo de comerciantes que todavía pretendía mantener su predominio en este mercado. Vicent acabaría encarcelado por la quiebra de la sociedad constituida. Pero la ferocidad del conflicto, larvado durante años en el seno de la Diputación del General, fue resultado del enfrentamiento enconado de dos bandos aristocráticos de posiciones antagónicas: por un lado, los caballeros Galceran de Montsoriu, señor de Estivella, y Nicolau de Pròixita, señor de Almenara, obcecados en labrarse una posición privilegiada en el mercado, coordinando a mercaderes de menor enjundia; por el otro, los representantes de la élite de propietarios de la deuda púbica de la institución, que veían en el monopolio del arrendamiento la posibilidad de asegurar la percepción anual de los intereses devengados. La prolongación del conflicto, acentuado por la crisis política y económica que afectó a partir de mediados de la década, supuso el abandono del sistema de arrendamientos, sustituido por la recaudación directa, hasta su recuperación a finales de la década de 1460 (1452, septiembre 1 y 13 . ARV, Generalitat, n. ${ }^{\circ} 2420 ; 1454$, marzo 9. Ibidem, n. ${ }^{\circ} 2422 ; 1457$, enero 11. Ibidem, n. ${ }^{\circ} 2676 ; 1459$, junio 22. Ibidem, n. $\left.{ }^{\circ} 2.427\right)$.

24. La recuperación del sistema de arrendamiento a partir de 1469 y su prolongación hasta 1492 fue posible por la sucesión de una serie de sociedades arrendatarias donde el predominio 
ENRIQUE CRUSELLES GÓMEZ

EL ENSUEÑO OCEÁNICO: LOS MERCADOS FINANCIEROS DE UNA PLAZA INTERREGIONAL EN ÉPOCA DE RECESIÓN (VALENCIA, 1480-1520)

mismo desenlace ${ }^{25}$. Los dos sistemas recaudatorios permanecieron en manos de la nobleza hasta su colapso. Comenzada la década de 1490, cuando era evidente que el esfuerzo financiero exigido por esas estrategias aristocráticas era nocivo para sus patrimonios, la recaudación fiscal de la Diputación del General quedó en manos de los maestros artesanos de varias de las más importantes corporaciones de la ciudad ${ }^{26}$.

aristócratico estuvo secundado por el apoyo de nuevos ricos y comerciantes de ascendencia conversa. Los Carroç de Vilarragut, Berenguer Vives de Böil, Gener Rabassa de Perelló, Pere de Castellví, Antoni Joan, señor de Tous, Manuel Llansol, señor de Gilet, Guillem Mascó, Galceran Bou, señor de Alginet, o Joan Pardo de Lacasta, por citar algunos, en muchos de aquellos años bajo la gestión societaria del doncel Joan Ram Escrivà, quien por entonces se convertiría en maestre racional del reino, fueron acompañados por los descendientes de los mercaderes de la primera mitad de siglo, convertidos ya en «ciutadans honrats» o caballeros (Pere d'Eixarch, Lluís Bou, Lluís Pellicer, Miquel Andreu, Lluís Llorach, Bernat Penya-roja) y por comerciantes y ciudadanos conversos (Gonçal Roís, Francesc Esparça, Manuel Esparça, Joan Nadal, Joan Valleriola, Lluís Nadal, Lluís Santàngel, Galceran Santàngel, Bernat Macip, Gisbert Tolosa, Ausiàs Pintor) (1469, enero 14. Ibidem, n. ${ }^{\circ}$ 2685; 1471, diciembre 30. Ibidem, n. ${ }^{\circ} 2688 ; 1485$, octubre 29. Ibidem, n. ${ }^{\circ} 2698 ; 1477$, diciembre 15. Ibidem, n. ${ }^{\circ} 2690 ; 1481$, enero 8. Ibidem, n..$^{\circ} 2694 ; 1484$, enero 14 . Ibidem, n. ${ }^{\circ} 2697 ; 1487$, enero 3 Ibidem, n. $^{\circ} 2700$ ).

25. Resultado de un proceso paulatino de concienciación de la obligada protección de sus intereses financieros, el 30 de mayo de 1482, la aristocracia urbana acabó reuniéndose en la cofradía de Sant Jaume para tomar la decisión de acaparar una parte de los arrendamientos de los impuestos municipales, los principales de la mercadería, de la carne y del «tall del drap», a fin de asegurar «lo redreç de pagaments dels censals que los sobredits e molts altres han e tenen sobre la dita ciutat», es decir, el cobro de los intereses de la deuda pública. Ya antes, en la segunda mitad de la década de los años setenta, Joan Ram Escrivà y su hermano mayor Eiximen Perez, quien se convertiría en lugarteniente y gobernador general del reino de Cerdeña, entre 1479 y 1486, y lugarteniente general del reino de Mallorca, entre 1486 y 1491, avalados por el conde de Cocentaina, Joan Roís de Corella, se habían hecho con el control de algunas de esas «sisas». Diez años más tarde, con la juradería de 1487, las imposiciones más rentables de la ciudad quedaron definitivamente en manos de aristócratas y ciudadanos honrados, destacando entre otros los nobles Francesc Vives de Boïl, señor de Bétera, Gaspar de Castellví, señor de Carlet, y Manuel Diez, señor de Andilla, o los ciudadanos Berenguer Martí de Torres y Bernat Penya-roja (Cruselles, 2018: 204-206).

26. A finales de 1490, el arrendamiento quedó en manos de los nobles Tomàs de Pròixita y Gaspar de Castellví. Sin embargo, entrado el nuevo año, estos habían renunciado al arrendamiento y el hijo del escribano de la sala lo traspasó a un consorcio de ocho oficios artesanales de la ciudad (pelaires, tintoreros, pañeros, terciopeleros, sastres, tundidores, calceteros y ropavejeros), acompañados por unos pocos particulares. Tras dos años de un primer arrendamiento, los mismos oficios obtuvieron el arrendamiento del periodo 1493-1495. El éxito por el acceso a estos negocios ruinosos se vio ensombrecido por el encarecimiento del precio del arrendamiento: de los 428.000 sueldos anuales que se habían pagado durante el trienio 1487-1489 a los 462.500 y 482.200 sueldos anuales que debieron aportar los oficios en cada uno de los dos periodos de arrendamiento (1490, diciembre 15 y 22. ARV, Generalitat, n. ${ }^{\circ} 2703 ; 1491$, enero 23. Ibidem, n. ${ }^{\circ} 2704 ; 1493$, enero 2 . Ibidem, n. ${ }^{\circ}$ 2706). Parece probable que, siguiendo el caso de la corporación de pelaires, la participación de los ocho oficios en el arrendamiento de los impuestos de la Diputación del General fuera resultado tanto de la pujanza de la industria artesana local 
Y aunque solo fuera por unos años ${ }^{27}$, como se ha mencionado en el caso del mercado financiero de seguros marítimos, la fragilidad del grupo mercantil había permitido el acceso del mundo artesanal, cuya riqueza acumulada sería también exprimida en beneficio del sistema económico urbano ${ }^{28}$.

Pero, además, el sistema económico urbano, en evidente deterioro, ya no procuraba estímulos a la inversión y a la actividad económica, ni a los mercaderes que habían quedado solos al frente de los negocios, ni a los recién incorporados, los artesanos. En todo caso, la ciudad seguía mostrando un interés incuestionable -materializado en la concesión de ayudas a los importadores- en asegurar el aprovisionamiento alimentario de su mercado, lo que le acarrearía no pocos problemas a finales de siglo ${ }^{29}$. Normal, los ediles se jugaban su cargo e incluso su vida en ello. Sin embargo, el resto de políticas de subvención y animación de la actividad mercantil, materializadas a principios de siglo en ayudas a la construcción naviera, el mantenimiento de flotas, la ordenación urbana o la preservación de infraestructuras

durante la época de crecimiento como de las reformas institucionales que experimentaron con el inicio de la recesión y de la necesidad de dar respuesta a la creciente competencia de nuevas industrias exportadores instaladas en plazas urbanas emergentes de la época. El esfuerzo financiero que exigió esta estrategia también debió influir en el decaimiento de estas industrias y su ruina entrado el siglo XVI. Aplicado al caso de los pelaires, «en la segunda mitad del siglo XVI el gremio de los pelaires de Valencia estaba más arruinado y perdido que nunca. Los maestros del oficio ya no tenían casas ricas sobradas de patrimonio y negocios como antaño, en la Edad Media» (Navarro, 2018: 299).

27. En los años siguientes, entre 1496 y 1501, los representantes de las corporaciones fueron perdiendo presencia en las sociedades arrendatarias frente al avance de un grupo de caballeros (Joan Albert, Manuel Eixarch, Gaspar Mascó, Francesc Amalrich y Lluís Corts), secundados por algún mercader (1495, diciembre 31. Ibidem, n. ${ }^{\circ} 2709 ; 1499$, enero 2. Ibidem, n..$^{\circ}$ 763). Hasta esas fechas, las imposiciones recaudadas en la capital siguieron estando bajo el control de la aristocracia urbana y, a lo sumo, artesanos y mercaderes actuaban más como testaferros y auxiliares necesarios de las estrategias elitistas de acaparamiento.

28. Un breve listado de los comerciantes, incluyendo algunos de ascendencia conversa, otros de pasado artesanal, que participaron con distinta frecuencia en los arrendamientos de las «sisas» municipales sería: Martí Abat, Galceran Adret, Jaume Alegre, Joan Allepús, Enric Barberà, Bernat Climent, Jaume Climent, Miquel Climent, Jaume Ferrer, Miquel Ferrer, Andreu Gil, Antoni Gil, Francí Gil, Lluís Gil, Jaume Gonbau, Joan Macip, Pere Macip, Jaume Marga, Gabriel Monrós, Lluís Monrós, Jaume Nadal, Miquel Oliver, Gil d'Anton Rois, Antoni Rull, Gaspar Rull, Joan Salvador, Pere Sanctes, Martí Santàngel, Joan Solanes, Pere Vidavia y Alfons Yunyes. De esta treintena, pocos, muy pocos, mantuvieron constancia en este mercado, dando la impresión de que buena parte de ellos actuaron a la sombra o como clientela de la aristocracia y la ciudadanía que acaparaban los mejores arrendamientos. De esta nómina, menos de una decena figuran en los listados antes citados de mercaderes más activos de la época o de mayores aseguradores en el registro de 1499 de Jaume Salvador, y algunos eran conversos (resaltado en cursiva).

29. Desde el arranque de la década de 1480 se inició un periodo de carestía de trigo en la capital que se reproduciría al comienzo del nuevo siglo (Belenguer, 2012: 126-151 y 309-312). 
vitales, desapareció ${ }^{30}$. Y con la desaparición de estas políticas, las sinergias que habían acompañado la actividad de las empresas mercantiles se diluyeron.

El ahogamiento del sistema económico se aprecia asimismo en el último de los mercados financieros que queda por analizar, el mercado del crédito y el sector bancario valenciano. No es fácil clarificar la envergadura de este núcleo de negocios a lo largo de un periodo temporal tan extenso. En la época que abarca los años 1240-1320, se menciona la recopilación de una nómina de medio centenar de «campsores Valencie», entre hebreos y cristianos (García Marsilla, 1995: 130-133), lo que implica como promedio generacional una quincena de banqueros. Desde esta etapa fundacional del reino, el ejercicio de la profesión ya abarcaba, por un lado, el cambio de moneda necesaria en la circulación mercantil y, ligado a ella, la transferencia interregional de capitales y, por el otro, la banca de depósito, las «comandes de dipòsit» que se hacían en sus «taules», que facilitaba la compensación de cuentas entre clientes, derivando asimismo en la transferencia de capitales, más a menudo local que interregional. La acumulación de dinero permitía a estos cambistas ampliar sus negocios y dedicarse a la actividad mercantil a lo largo de las redes de distribución valencianas, estableciéndose una escasa diferencia de negocios entre el mercader y el banquero interregionales. Sin embargo, el desarrollo del mercado crediticio privado a lo largo de los dos siglos siguientes bajo fórmulas apoyadas por las instituciones políticas, como el censal o el violario (García Marsilla, 2002), que permitían emplear capitales a ciudadanos y aristócratas y obtener beneficios del crédito, debió limitar el recurso de la comunidad urbana a bancas y empresas mercantiles habitual en otras sociedades que, como la florentina, conocieron un mayor desarrollo del capital mercantil.

Durante la primera mitad del siglo XV, el número de bancas siguió siendo limitado, una veintena aproximadamente, donde se advierte el creciente peso de los cambistas de ascendencia conversa ${ }^{31}$. La documentación de la segunda mitad

30. No existe análisis sistemático sobre estos aspectos y debemos contentarnos con algunos datos esporádicos y algunas reflexiones heurísticas. Respecto a estas, solo apuntar los cambios que se observan en los contenidos de las decisiones acordadas por los munícipes recogidos en los «Manuals de Consell», centrados en los años finales de siglo en cuestiones políticas y diplomáticas cuando un siglo antes abordaban constantemente la organización económica del municipio, de tal manera que las necesidades imperiosas, como la amenaza corsaria o la restauración de infraestructuras, se resolvían mediante la creación de una tasa fiscal puntual o se trasladaban a tesorerías secundarias como la «Sotsobreria de Murs i Valls». En este sentido, llama la atención que la «Claveria Comuna», oficina encargada de la financiación de estas políticas económicas, fue progresivamente despojada de recursos financieros en beneficio de las otras dos destinadas a afrontar la gestión de la deuda pública del municipio (Cruselles, 2018: 202-204).

31. El listado, procedente de las mesas notariales, es por ahora incompleto, con algunos casos de banqueros conversos confirmados marcados en cursiva: Barnabàs Almenara, Francesc d'Arins, Joan Belluga sr., Llorens Belluga, Guillem Casasagia, Antoni Castelló, Ramon 
de la centuria aventura un sector de dimensiones similares, donde el predominio converso era ya aplastante ${ }^{32}$, si bien la tendencia política de finales de siglo marcaba su espantoso final. Valga un episodio para mostrar la imposible huida de ese destino. Corría el año 1486. El converso Lluís de Santàngel, escribano de ración del monarca, compareció ante el gobernador general del reino ${ }^{33}$. Llevaba consigo una carta real datada en Córdoba dos años antes. En ella Fernando II refería que «alguns de aqueixa ciutat nos offeriren servir per a la guerra de Granada» nueve mil libras, decidiéndose que «per traure aquelles fon feta certa tacha», en la que intervino su hombre de confianza. Hacía otros dos años que se había retomado la guerra de Granada y no sabemos con certeza a quién se refería el monarca con ese ofrecimiento ${ }^{34}$, aunque por las personas mencionadas suponemos que era una manera eufemística, si no cínica, de referirse a la extorsión con la que trataba a la comunidad conversa para arrebatarle dinero con el que financiar sus ambiciones políticas $^{35}$. Sin embargo, la recaudación había planteado problemas: «E perquè en la dita tacha hi havia molts hòmens pobres e no·s podien acabar de exhigir los diners que aquells havian a pagar», Santàngel había adelantado personalmente aquel dinero y conseguido el apoyo real para constreñir «als richs» a que facilitaran el dinero de sus conciudadanos que quedaba por pagar. Aparte de que Santàngel no había recuperado todo el dinero adelantado, eran aquellas «opulents e riques» personas las que le reclamaban en 1486 la devolución del dinero avanzado, que él consideraba

Castrellenes, Miquel d'Eivissa, Gabriel Falcó, Joan Garcia, Jaume Garberà, Gabriel Falcó, Lluís Gasó, Jofré de les Escales, Bernat Estellers, Gabriel Just, Bernat Llibra, Bernat Peris, Tomàs Pujades, Lluís Ros, Simó Sacreu, Francesc Siurana, Joan Talamanca, Guerau Traver y Miquel Vilaginers.

32. Los banqueros de ascendencia conversa asegurada confirmada se muestran en cursiva: Francesc d'Artés, Joan Belluga jr., Lluís Belluga, Gracià Dezvalls, Jofré de les Escales jr., Sancho Ferrandiz, Gabriel Just, Genís Just, Pere Mir, Daniel Pardo, Francesc Pérez, Ausiàs y Bernat Pintor, la banca Roís, Francesc Salvador, Joan Sebastià, Lleonart Serra, Lluís Serra, Lluís Talamanca, Alfons Tacle, Gabriel Torregrossa y Manuel Torregrossa.

33. ARV, Gobernación, n. ${ }^{\circ} 2380, \mathrm{~m} .21, \mathrm{ff} .42-46$.

34. Por ahora solo se tiene constancia de que, en aquellos años, el municipio había reducido sus donaciones de dinero al monarca a dos ocasiones, una en 1479, otra en 1484-1485, consecuencia de las dificultades financieras que lo asfixiaba, luego no parece probable que se tratara de un préstamo institucional (Belenguer, 2012: 120-121).

35. En mayo de 1482, los hombres de finanzas del rey llevaban a cabo la negociación con la comunidad conversa valenciana sobre la recuperación de los bienes de parte de los reconciliados y procesados no condenados a penas graves («por restaurar los bienes de los que avían incedido en crimen de eregía»). La composición colectiva surgida de esta negociación se concretó en el mes de septiembre y desembocaría en una tacha que recogería el dinero de los afectados, si bien había quien se negaría a pagar. Manteniendo el mismo tono en el lenguaje, el monarca hacía referencia a que los conversos valencianos habían decidido hacer a la corona «cierto servicio pecuniario", lo que no impedía a Fernando II recurrir a sus oficiales y administradores para constreñir a pagar a los afectados (Cruselles, 2018: 134-135). 
prestado no a su persona sino a la tacha y que, por tanto, debía reintegrar esta. Era lo que exigía que promulgase el gobernador, al que Santàngel apuntaba el nombre de esos ricos hombres de negocios: Gisbert Tolosa, Joan Sànchez, Pere Bellviure, Salvador Vives, Jofré de les Escales, Gil d'Anton Roís, Galceran Adret, Lluís Monrós, Miquel Ferrer, Lluís Serra y Lluís Conca. Este procedimiento demuestra que esos grandes comerciantes y banqueros de la comunidad de ascendencia conversa eran conocidos por las instancias públicas gracias a los conciudadanos que, como Santàngel, trabajaban para esos poderes. En este contexto, sin poder hacer por el momento una evaluación exhaustiva de la documentación inquisitorial, el número de banqueros de origen converso represaliado por la monarquía, despojado de su riqueza y prácticamente aniquilado, alcanzaba la veintena ${ }^{36}$.

De aquí pueden extraerse dos conclusiones relacionadas. Por un lado, el desarrollo mercantil de Valencia no solo había atraído desde sus orígenes empresas extranjeras, principalmente de las ciudades del norte de la península itálica, si no que, desde mediados de la centuria, en la época en la que la vieja élite mercantil comenzaba a retirarse de los negocios, algunas de estas empresas comenzaron a cobrar un cariz eminentemente bancario, especializándose en la prestación de servicios financieros tanto a los mercaderes como a los ciudadanos valencianos, facilitando su relación con las redes urbanas europeas. De este modo, el progresivo vacío dejado por la banca local sería ocupado por el capital mercantil foráneo: 27 de los empresarios, corresponsales y factores de origen itálico afincados en Valencia entre 1471 y 1499 se dedicaron, entre otras actividades, al crédito en el mercado local (Igual, 2000: 135; Igual, 2003: 406 y 411).

Además, es el segundo factor, desde su consolidación a finales del siglo XIV, la actividad de la banca local había estado ligada al sistema financiero urbano y, en general, político. La gestión de cualquiera de las tesorerías públicas que recaudaban dinero (las claverías municipales, los tres justicias, el «sotsobrer de murs i valls», el clavario de la Diputación, los hospitales, etc.) exigía de la colaboración de un mercader, preferentemente de un banquero, que cumplía la función de caja fuerte al servicio

36. Daniel d'Artés (1491), Francesc d'Artés (1506), Joan Belluga jr. (1506), Lluís Conca (1495), Jofré de les Escales (1497), Jofré de les Escales jr. (1506), Alfonso Ferrandis (1514), Enric Fuster (1529), Miquel Piera (1503), Ausiàs Pintor (1492), Bernat Pintor (1488), Benet Pròixita (1497), Francesc Salvador (1499), Joan Sànchez (1491), Gaspar Sayes (1491), Lleonart Serra (1490), Lluís Serra (1497) y Gabriel Torregrossa (1493-1495). Las fechas de sus procesamientos finales es aproximada. Se debe tener en cuenta que, con el asentamiento del primer tribunal en la Navidad de 1481, comenzaron las acusaciones contra muchos de ellos y el hecho de salvarse temporalmente del patíbulo o de conseguir morir en su cama de muerte natural no les libraría de que el Santo Oficio fuera progresivamente arañando su patrimonio, tanto por reconciliaciones generales, composiciones o acusaciones directas contra ellos más tardías como por procedimientos incoados contra sus hijas y viudas, hasta acabar destruyendo finalmente sus redes de sociabilidad y absorbiendo el resto de su patrimonio. 
del cargo público. A ellos se acabarían uniendo también los arrendatarios de los impuestos municipales y del General. A pesar de que en Valencia no sobrevivió un banco municipal que congregara la actividad de todas las bancas privadas puestas al servicio de los poderes e instituciones públicos ${ }^{37}$, sí se preservó la función sistémica que aquella cumplía ${ }^{38}$. Es el caso, por ejemplo, de la relación mantenida entre el Justicia Civil y su «taulager», que era el clavario del «Quitament», a veces sustituido por su lugarteniente, que era el banquero de turno. La retención en la caja del dinero depositado por demandados, deudores y posibles futuros herederos facilitaba liquidez monetaria al oficial municipal a la hora de saldar la deuda municipal. Por tomar una primera referencia de una época temprana, en 1436, el «taulager [del Justicia Civil] e clavari dels quitaments» era el mercader Daniel Barceló. Unos años más tarde, entre 1442 y 1445, ambas funciones recayeron en Galceran d'Eixarch, miembro de otra familia mercantil en vías de promoción social, al que sucedió Lluís Blanch, un hombre de negocios más de la primera mitad de siglo, que se alternaría en el puesto con Joan Amat hasta 1450. Les seguiría uno de los grandes cambistas de mediados de la centuria: Miquel d'Eivissa, quien ya no era clavario del «Quitament», cargo que se compaginaba con el de «taulager» del Justicia Civil, si no «tenintloch del taulager», designación apropiada para un banquero (quizá converso) que gestionaba ambas tesorerías. Así se mantuvo hasta 1461. Tras un breve período en que el cargo fue retenido por ciudadanos advenedizos, a mediados de la década de 1470, la banca de Ausiàs y Bernat Pintor trabajó como «regents de la taulageria» de la corte del Justicia Civil durante varios años (Igual, 2016) ${ }^{39}$. De la misma manera, en esa época la banca Roís abrió sus cajas al dinero recaudado por la sociedad arrendataria del impuesto municipal de la «mercaderia», en aquella época acaparado ya por la aristocracia y gestionado por mossèn Lluís Crespí de Valldaura ${ }^{40}$. Otros comerciantes conversos, de menor enjundia, cumplieron una función similar como gestores de

37. El fracaso del primer intento de creación en Valencia de una tesorería pública centralizada, la «taula de canvi» municipal, que solo perduró entre 1408 y 1416, permitió la resistencia de la banca privada a la sombra de las instituciones públicas, hasta que el agotamiento definitivo de este modelo, con la bancarrota de la banca Forés, obligaría a reinstaurar la banca pública en 1519 (Carreres, 1957).

38. La «Taula de canvi assegurada de la Ciutat de Barcelona», de vida estable y no episódica como la de Valencia, aglutinando toda la tesorería municipal, tuvo por principal objetivo concentrar los ingresos fiscales y los depósitos forzosos, y con ellos conseguir amortizar deuda pública, si bien no correspondía al clavario de la ciudad su gestión, como en el caso valenciano (Feliu, 2016: 38-39).

39. ARV, Justicia Civil, n. ${ }^{\circ} 891$; n. ${ }^{\circ} 901$, m. 11 f. 46; n. ${ }^{\circ}$ 907, m. 12, ff. 20v.-21; n. ${ }^{\circ}$ 908, m. 21, f. 46; n. ${ }^{\circ} 913$; n. ${ }^{\circ} 915$, m. 12, f. 2 ; n. ${ }^{\circ} 917$, m. 15, f. 41 y m. 16, f. 44; n. ${ }^{\circ} 919$, m. 12, f. 29 v.; n. ${ }^{\circ} 920$, m. 8, f. 26; n. ${ }^{\circ} 4020$, m. 11, f. 22 ; n. ${ }^{\circ} 925$, m. 6, f. 15 у 42, у m. 8, f. 11-12, 29 y 49; n. ${ }^{\circ}$ 929 , m. 11, f. 13.

40. Archivo Histórico Nacional, Inquisición, leg. 5320, caj. 3, exp. 19, f. 5. 
dinero ajeno, generalmente de las rentas de señoríos cuyos titulares habían dirigido la canalización de sus preciados excedentes agropecuarios hacia las redes comerciales marítimas europeas, en un ejemplo más de la implicación de la aristocracia en la gestión empresarial ${ }^{41}$.

El debilitamiento del sector bancario local empujó a la élite política a buscar nuevos gestores, siendo según los datos los primeros elegidos las bancas internacionales. Es conocido el ejemplo de los Spannochi como banquero de las rentas pontificias de la casa Borja (Cruselles e Igual, 2003). También son los casos algo menos trabajados del genovés Francesco Palomar o del sienés Battista Burgarini. Activo en Valencia desde 1475, el ligur, que era tratado al principio indistintamente como terciopelero y como mercader, se especializó una década más tarde en la transferencia de capitales, poniendo su red empresarial al servicio de comerciantes locales. Tras un lustro de viajes visitando sus distantes negocios, desde Canarias hasta Barcelona, en el verano de 1499 , adquirió la ciudadanía valenciana ${ }^{42}$. Para entonces ya había anudado relaciones con la familia zaragozana de los Sánchez. Y también para entonces disponía de una «tabula cambii» en la ciudad y mantenía relaciones con las principales plazas financieras de Europa. Entre 1500 y 1503, su «Banco de Valencia» fue investigado por la corona castellana por la extracción fraudulenta de oro enviado a Valencia, donde la escasez de metal precioso le procuraba suculentos beneficios. Aún sobreviviría una década a la sentencia condenatoria.

El sienés llegó más tarde a la ciudad, hacia 1485, actuando como «iuvenis» y factor de los Spannochi, a la sombra de los cuales hizo sus primeros pinitos en el

41. Así, coetáneo de los Roís, Francesc Esparça, antes tendero y después mercader, fue durante bastantes años el administrador de las rentas de Pere Maça de Liçana alias Lluís Cornell, señor de Moixent y Novelda, entre otros títulos, al tiempo que organizaba la comercialización de sus cosechas. Años antes había hecho lo propio con el valle de Villalonga y el lugar de Anna, de mossèn Jofré de Borja (1475, mayo 6. Archivo de Protocolos del Real Colegio del Corpus Christi de Valencia -en adelante APCCV-, protocolo n. ${ }^{\circ} 11379$, Manuel Esparça; 1483, junio 26. Ibidem, n. ${ }^{\circ}$ 19037, Jaume Gisquerol; 1469, abril 17. Ibidem, n. ${ }^{\circ} 11140$. Manuel Esparça). Rafael de Bellpuig, mercader converso y pariente de los Roís, había arrendado a los Pròixita las rentas de Alcosser y Gabarda (1466, octubre 18. Ibidem, n. ${ }^{\circ} 11371$, Manuel Esparça). También las rentas de la baronía de Chiva, titularidad de la familia Moncada, pasaron por las manos de Joan Belluga durante varios años (1471, mayo 31. Ibidem, n. $\left.{ }^{\circ} 11375\right)$.

42. AMV, Llibres de aveïnaments, $\mathrm{g}^{3}-8, \mathrm{f}$. 134v. (1499, junio 27). A pesar de no cumplir las condiciones preceptivas para adquirir la ciudadanía valenciana, por cuanto no había presentado documento alguno que demostrara su renuncia a la genovesa, los jurados le concedieron la nueva condición. Esta laxitud de las autoridades municipales se evidencia también en otros casos, como el del sienés Pietro Spannochi, en cuyo juramento prometió que en el plazo de un año entregaría el documento de su desavecindamiento de la ciudad de Siena, sin que ningún acto jurídico añadido más tarde confirme que lo hiciera, y viene a evidenciar la necesidad de atraer a estos conspicuos hombres de finanzas en una época de crisis (Ibidem, f. 133. 1498, noviembre 26). 
mercado de cambios negociando a lo largo de las redes financieras europeas. Una década más tarde intensificó su vinculación con la ciudad del Turia, se independizó de sus jefes y formó su propia compañía, «Batista Bulguerini e company», extendiendo sus tratos desde Castilla hasta la península itálica y diversificando su actividad desde el transporte marítimo hasta los negocios financieros, más allá de la extensión de pólizas de seguros marítimos, aspecto que ya ha sido mencionado. Finalmente, a finales de febrero de 1509, se avecindó acabando por trasladar su domicilio a la parroquia de Sant Nicolau, donde en la actualidad una calle Burguerins recuerda aún su paso por esta ciudad (Ladero, 1987; Igual, 1996: 181-190 y 274-279).

Entrada la nueva centuria, quizá desde antes, la aristocracia urbana, que mantenía el control sobre varias sisas de la ciudad, llegó a tratar con Burgarini. Son unos capítulos firmados entre mossèn Francesc Crespí de Valldaura, caballero que representaba a los «parçoners» del capítulo de las carnes, con el factor del sienés. Según el acuerdo, Burgarini aceptaba girar letras de cambio sobre Cuenca, Toledo y Sevilla por valor total de unos 10.000 castellanos de oro para financiar la compra de ganado, que la sociedad arrendataria reembolsaría en Valencia. Los negocios con los arrendatarios se prolongaron a lo largo del año $1503^{43}$. El crecimiento de su banca en Valencia siempre estuvo ligado a sus relaciones con aquella élite política. En 1515, aun teniendo la ciudadanía valenciana, seguía siendo denominado como «mercader senès resident en la present ciutat de València mercatívolment, taulager e o tenent taula de cambi dins la longa de la present ciutat» ${ }^{44}$. Con ese banco asegurado, Burgarini continuó en los negocios del suministro municipal de carne del que acabaría adquiriendo su monopolio, cuando el experimento Forés había llegado a su fin (García Cárcel, 1975: 93).

Palomar mantuvo también una estrecha relación con aquella élite política. Cuando ya disfrutaba de su condición de ciudadano valenciano, colaboró desempeñando la función subalterna que habían cumplido hasta entonces los comerciantes conversos. En 1502, actuaba como procurador del clavario del «Quitament» $\mathrm{y}$ «taulager» de la corte del Justicia Civil, haciendo transferencia de capitales ${ }^{45}$. En 1503, cuando se estaba ventilando su proceso en Castilla, el Justicia Civil requería que él y su socio «taulager» Pedro Sánchez, «e o als regents de la taula» reembolsaran a la heredera un depósito de dinero que un difunto doncel había impuesto en su «taula vulgarment dita de València» ${ }^{46}$. Sin embargo, el banco no debió sobrevivir a las pesquisas oficiales. En la primavera del año siguiente, se designaban árbitros para liquidar las

43. 1503, febrero 23, marzo 21, septiembre 19 y junio 20 (ARV, Protocolos, n. ${ }^{\circ} 2020$. Jaume Salvador).

44. 1515, noviembre 26 (APCCV, protocolo n. ${ }^{\circ}$ 12612. Guillem Ramon Florença).

45. ARV, Justicia Civil, n. ${ }^{\circ}$ 937, m. 7, f. 13.

46. Ibidem, n. ${ }^{\circ} 938$, m. 8, f. 14. 
cuentas del banco ${ }^{47}$. La «taula de canvi» había sido constituida en 1499 por Pedro Sánchez y Francesc Palomar, «la qual taula fonch assegurada» por los hermanos del primero, Gabriel Sánchez, tesorero real, y su lugarteniente Alfonso, junto con sus mujeres, "perquè tots los qui negossiaven en aquella poguessen segurament negossiar». Su gestión había quedado a cargo de Palomar, pero

regoneguts los libres de la negossiació se trobe que lo dit micer Francisco Palomar ha rebut moltes e diverses quantitats de les quals no ha donat ne dona complida desexida, per la qual rahó los qui han negossiat en la dita taula e crehedors de aquella de continu demanen, han demanat e cominen voler demanar lo que pretenen ésser-los degut.

Seguramente, los problemas judiciales en Castilla habían destapado la caja de Pandora y destruido la confianza entre los socios, Palomar y la familia Sánchez, sus fiadores ${ }^{48}$, por lo que estos, para evitar cualquier responsabilidad jurídica, pedían la elección de jueces contadores a los que dar «compte e rahó de les rebudes e dates que són stades fetes en la dita taula e que paguen lo residum».

Los dos bancos de oriundos italianos, naturalizados valencianos, trabajaron con Onofre Ferrer, el mercader cuyo libro de cuentas citábamos al principio. Con Pedro Sánchez y Francesco Palomar, entre 1501 y 1503; con Burgarini, entre 1508 y 1514, aproximadamente. En ambos casos, Palomar en 1499 y Burgarini en 1509, los propietarios tuvieron que naturalizarse antes de abrir sus «taules assegurades» en Valencia, lo que les permitía instalarse en un sitio privilegiado, dentro de la lonja de la ciudad, donde tenían lugar los principales actos institucionales que afectaban al mundo de los negocios. Entre medias, una parte de las transferencias y compensaciones de deudas con sus clientes fue llevada por Ferrer a través de la «taula» de Jeroni Torres y Baltasar Forés, de la que se conserva menciones en su libro mayor entre el verano de 1504 y la primavera de 1509. En la creación de su banco, Forés debió cumplir rituales de naturalización similares a los de los mercaderes itálicos ya comentados $^{49}$. El notario Jaume Salvador lo registraba en el «llibre de seguretats» de 1499 como tendero, cuando aún iniciaba su carrera profesional. Era natural de

47. 1504, marzo 20 (Ibidem, n. ${ }^{\circ} 939$, m. 2, f. 15 y n. ${ }^{\circ} 940$, m. 8, f. 26).

48. También hay que recordar que otra banca, la de Alfonso Sánchez, el ubicuo lugarteniente del tesorero real, fiador del «banco de Valencia» de Palomar-Sánchez, había sido señalada por fraude en 1503 dando lugar a una investigación y a una nueva crisis de las finanzas locales (Belenguer, 2012: 312-320).

49. Aunque no se ha conservado acta de avecindamiento, es probable que hubiera existido por cuanto han desparecido los registros de avecindamientos entre 1490 y 1494 . Además, tampoco es extraño en la época que a un natural del reino se le reconozca la ciudadanía tras enlazar matrimonialmente con una familia de la ciudad, en este caso, de modestos antepasados, como podría calificarse la de su socio y cuñado. 
Cocentaina, villa donde había acumulado capital obtenido en la industria textil de la lana. En fecha incierta pasó a Valencia y, desde entonces, inició un ascenso profesional meteórico que, al decir de algunos, le llevó a convertirse en uno de los hombres de negocios más importantes de la ciudad (Igual y Navarro, 1994). Sin llegar a afirmar ahora esa conclusión de manera tan categórica, parece más probable que Forés se integrara mejor en el grupo de los nuevos hombres de negocios curtidos en el mercado local: sin haber desarrollado una vida empresarial en los mercados exteriores como había sido costumbre en la profesión hasta entonces, no solo dio el salto fugaz al grupo mercantil con el cambio de siglo sino que se puso al servicio de la élite política, constituyendo un banco de solvencia, cuanto menos, quebradiza. De esa élite obtuvo toda una serie de prebendas (cargos contables como el de clavario o de «taulager» de diferentes oficinas municipales, arrendamientos de algunas sisas y la gestión financiera de otras), reproduciendo en buena medida las estrategias mantenidas durante el siglo anterior, pero hasta tal grado de acaparamiento y monopolio que acabaría confundiendo la gestión del dinero público con la del negocio privado y aprovechándose de la opacidad para esconder prácticas corruptas como fue la colocación fraudulenta de deuda pública previamente amortizada. Todo ello es bien conocido a partir de la investigación que se abrió tras la quiebra del banco, producida a finales de 1511, que arrastró a una crisis de liquidez a las finanzas municipales y de legitimidad a las instituciones de gobierno (Belenguer, 1975; Belenguer, 2012:344-358). Sin embargo, no es esa parte conocida de la historia la que nos interesa remarcar ahora, sino por el contrario el origen de ese conato de efervescencia empresarial, porque delata bien las dificultades económicas por las que pasaba la economía urbana valenciana y el juego soterrado e incontestado de las élites políticas, que ya no solo decidían qué bancos debían gestionarles los negocios públicos sino que incluso decidían la constitución de bancos a su antojo.

A mediados de mayo de 1504, cuando hacía unos pocos años que disfrutaba de su condición mercantil, y el mismo año en que aparece mencionado por primera vez en el libro de cuentas de Onofre Ferrer, Baltasar Forés presentó un requerimiento al Justicia Civil ${ }^{50}$. Quería constituir una «taula assegurada» junto a su cuñado Jeroni Torres. Recordando la legislación regia al respecto, la pareja quería entregar al oficial municipal las fianzas obligadas, que le otorgarían un difuso prestigio social para atraer los depósitos de dinero ${ }^{51}$. Para superar los mil marcos de plata que fijaba la legislación foral, aseguraron primero su banco con las garantías acordadas con sus

50. 1504, mayo 15 (ARV, Justicia Civil, n. ${ }^{\circ}$ 940, m. 14, ff. 37-42).

51. El aval financiero del banco, desde la aplicación de la legislación de Jaime II en la segunda década del siglo XIV, facilitaba asimismo el procedimiento de promoción institucional: no solo la mesa del banco ocupaba un sitio preeminente en el interior de la lonja, sino que contemplaba que «cascun any lo Justícia Civil de la present ciutat de València ab pública crida notifique qui té taula assegurada e qui no la té assegurada», fórmula prestigiosa de publicidad empresarial. 
fiadores, miembros de la flor y nata local: el señor de Manises Pere Boïl (22000 sueldos); Leonor Boil i Pròixita, condesa de Aversa (55000); los nobles Pere Boïl jr. (55000), Joan Boïl (22000) y Joan de Cervato (22000); los caballeros Lluís Valleriola (11000), Manuel d'Eixarch (11000) y Joan Ram Escrivà, maestre racional del reino (22000); los donceles Antoni de Vich (44000) y Àngel d'Eixarch (11000); y los ciudadanos Francí Joan Dalmau (22000) y Berenguer Martí de Torres $(15000)^{52}$. Además de estas fianzas por un montante total de 312000 sueldos, Forés aportaba tres títulos de deuda municipal que sumaban un capital global de 16200 sueldos y dos casas, una en la parroquia de Santa Caterina y otra en la de Sant Martí. La finalidad de «parar la dita taula públicament en longa nova de la dita ciutat de València ab son tapit», distintivo de su carácter sobresaliente («molt excellent, tuta e segura»), era responder a la «penúria que en aquella [Valencia] és de taula e taules de cambi segures e assegurades». Parece evidente que el apoyo de las élites ciudadana y aristocrática, que controlaban los arrendamientos fiscales de las instituciones que gobernaban y que eran las principales compradoras de la deuda pública que tales arrendamientos respaldaban, obedecía a la necesidad de disponer de un banco que gestionara el depósito y la circulación de los recursos financieros, apoyando el cometido de las oficinas y cargos públicos. Es decir, recuperar de forma subrepticia la «taula de canvi» municipal que en el pasado lejano no había fraguado y que había sido parcheada durante bastante tiempo con el recurso a las pequeñas «taules» de mercaderes y banqueros locales.

Sin embargo, el lento declive de la economía urbana valenciana y la evolución política harían infructuoso el modelo, obligando a recurrir a operadores extranjeros y a experimentos forzados de reactivación del tejido empresarial local. A pesar de la difusión del bagaje técnico entre distantes sectores de la sociedad local, desde la aristocracia hasta el artesanado, y del amplio desarrollo de los mercados financieros que esas prácticas comerciales sustentaban, que hacían de Valencia una metrópoli de dimensión continental, el repliegue mercantil y el debilitamiento del entramado empresarial abocaba la sociedad valenciana a la pobreza y al conflicto. Superados los graves enfrentamientos surgidos con el brote agermanado que la brecha social había alimentado, en los que se reclamó la modificación del funcionamiento institucional, el declive era imparable: las décadas de 1530 a 1560 fueron las de menor actividad portuaria de aquella centuria, según demuestran las fuentes arancelarias, época que pasaba factura a las tradicionales metrópolis marítimas mediterráneas (Salvador, 1972: 334-336; Iradiel, 2017b: 376-379).

52. La nómina de fiadores fue modificándose algo con el tiempo. En mayo de 1506, la fianza de Joan Boil fue asumida por el señor de Manises. En diciembre de 1508, Jeroni Centelles sustituyó a Francí Joan Dalmau en la suya. 
ENRIQUE CRUSELLES GÓMEZ

EL ENSUEÑO OCEÁNICO: LOS MERCADOS FINANCIEROS DE UNA PLAZA INTERREGIONAL EN ÉPOCA DE RECESIÓN (VALENCIA, 1480-1520)

\section{BIBLIOGRAFÍA}

Aparici Martí, J. (2018). Bernat Sorell, tintorero, ciudadano de Valencia, señor de Geldo (primera mitad del siglo XV). En D. Igual Luis y G. Navarro Espinach (coords.), $E l$ País valenciano en la baja Edad Media. Estudios dedicados al profesor Paulino Iradiel (pp. 19-45). València: PUV.

Belenguer Cebrià, E. (1975). En torno a un proceso de malversación económica en la Valencia del Quinientos: la quiebra de 1511. Estudis. Revista de Historia Moderna, 4, 25-37.

Belenguer Cebrià, E. (2012). Fernando el Católico y la ciudad de Valencia. València: Universitat de València.

Carreres Zacarés, S. (ed). (1935). Libre de memòries de diversos sucesos e fets memorables $e$ de coses senyalades de la ciutat e regne de València (1308-1644). Valencia: Acción Bibliográfica Valenciana.

Carreres Zacarés, S. (1957). La taula de cambis de Valencia, 1408-1719. Valencia: Ayuntamiento de Valencia.

Cruselles Gómez, E. (2001). Los mercaderes de Valencia en la Edad Media (1380-1540). Lleida: Editorial Milenio.

Cruselles Gómez, E. (2006). Los mercados aseguradores del Mediterráneo catalanoaragonés. En Richezza del Mare. Richezza del Mare. Secc. XIII-XVIII (vol. I, pp. 611-63). Firenze: Le Monnier.

Cruselles Gómez, E. (2007). Los comerciantes valencianos y sus libros de cuentas. Castelló: Universitat Jaume I.

Cruselles Gómez, E. (2018). Hombres de negocios y ciudadanos honrados en Barcelona y Valencia en las postrimerías del siglo XV. En E. Belenguer Cebrià (ed.), Ferran II $i$ la Corona d'Aragó (pp. 195-212). Barcelona: Institut d'Estudis Catalans.

Cruselles Gómez, E. (2019). Fortuna y expolio de una banca medieval. La familia Roís de Valencia (1417-1487). València: PUV.

Cruselles Gómez, J. M. (1996). Ideales sociales y estrategias familiares en el mundo urbano. La ciudad de Valencia, 1485-1500. En L.M. Enciso Recio (coord.), La burguesía española en la Edad Moderna (vol. 3, pp. 1369-1383). Valladolid: Universidad de Valladolid.

Cruselles Gómez, J. M. (2018). Alternativas de una decisión: las confesiones voluntarias ante el tribunal del Santo Oficio (Valencia 1482). Revista de la Inquisición. Intolerancia $y$ Derechos Humanos, 22, 115-142.

Cruselles Gómez, J. M. y Igual Luis, D. (2003). El duc Joan de Borja a Gandia. Els comptes de la banca Spannochi (1488-1496). Gandia: CEIC Alfons el Vell.

Díaz Borrás, A. (1992). La Casa de Contratación de Orán y el cambio en la filosofía de las transacciones entre Berbería y Valencia, 1510-1514. Sharq Al-Andalus, 9, 19-27.

Feliu i Montfort, G. (2016). Els primers llibres de la Taula de Canvi de Barcelona. Barcelona: Fundació Noguera.

García Cárcel, R. (1975). Las Germanías de Valencia. Barcelona: Península.

García Marsilla, J. V. (1995). Crédito y banca en el Mediterráneo medieval: la quiebra del cambista valenciano Francesc de Pals (1316-1319). Anuario de Estudios Medievales, 25(1), $127-150$ 
García Marsilla, J. V. (2002). Vivir a crédito en la Valencia medieval. De los orígenes del sistema censal al endeudamiento del municipio. València: Universitat de València.

Guidi Bruscoli, F. (2018). Da comprimari a protagonisti: i fiorentini in Portogallo nel Basso Medioevo (1338-1520). e-Humanista: Journal of Iberian Studies, 38, 65-82.

Igual Luis, D. (1996). Valencia e Italia en el siglo XV. Rutas, mercados y hombres de negocios en el espacio económico del Mediterráneo Occidental (Tesis doctoral). Universitat de València.

Igual Luis, D. (2000). Los agentes de la banca internacional: cambistas y mercaderes en Valencia. Revista d'Història Medieval, 11, 105-138

Igual Luis, D. (2003). La banca extranjera en la Corona de Aragón a finales de la Edad Media. En El món urbà a la Corona d'Aragó: del 1137 als Decrets de Nova Planta. XVII Congrés d'Història de la Corona d'Aragó. Barcelona: Universitat de Barcelona.

Igual Luis, D. (2016). Los Pintor, cambistas valencianos (1473-1488): una aproximación al significado de los rasgos informales de la economía. En F. P. Iradiel Murugarren et al., Identidades urbanas Corona de Aragón-Italia: redes económicas, estructuras institucionales, funciones políticas (siglos XIV-XV) (pp. 75-92). Zaragoza: Universidad de Zaragoza.

Igual Luis, D. (2018). Los del Nero, mercaderes florentinos: familia, negocios y poder en los reinos hispánicos (1470-1520). En F. Sabaté (ed.), El poder entre la ciutat i la regió (pp. 219-250). Lleida: Pagès editors.

Igual Luis, D. (2019). Movimento portuale, reti marittime. Diversità dei mercati a Valenza nel XV secolo. En Reti marittime come fattori dell'integrazione europea. Maritime Networks as a Factor in European Integration (pp. 71-87).. Firenze: Firenze University Press.

Igual Luis, D. y Navarro Espinach, G. (1994). Ontinyent i València en temps de Baltasar Forés. Almaig. Estudis i Documents, 10, 105-109.

Iradiel, P. (2017a). Metrópolis y hombres de negocios (siglos XIV y XV). En P. Iradiel, El Mediterráneo medieval y Valencia. Economía, sociedad, historia (pp. 185-216). València: PUV.

Iradiel, P. (2017b). El comercio en el Mediterráneo entre 1490 y 1530. En P. Iradiel, El Mediterráneo medieval y Valencia. Economía, sociedad, historia. València: PUV, 367-400.

Ladero Quesada, M. A. (1987). El Banco de Valencia, los genoveses y la saca de moneda de oro castellana. 1500-1503. Anuario de Estudios Medievales, 17, 571-594.

Mainoni, P. (1982). Mercanti lombardi tra Barcellona e Valenza nel basso medioevo. Bolonia: Cappelli editore.

Navarro Espinach, G. (2018). El oficio de los pelaires de Valencia a través de sus asambleas de 1452-1481. En D. Igual Luis y G. Navarro Espinach (coords.), El País valenciano en la baja Edad Media. Estudios dedicados al profesor Paulino Iradiel (pp. 281-307). València: PUV, 2018.

Piffanelli, L. (2014). Il libro rosso seghreto di Bongianni Gianfigliazzi. Famiglia, affari e politica a Firenze nel Quattrocento. Roma: Edizioni di Storia e Letteratura. 
Rodrigo Lizondo, M. (2013). L'orgull del cavaller. L'ascensió del llinatge Sorell (València, ss. XIV-XVII). eHumanista/IVITRA, 4, 165-200.

Salvador Esteban, E. (1972). La economía valenciana en el siglo XVI (comercio de importación). Valencia: Universidad de Valencia.

Salvador Esteban, E. (2008). Un aragonés en la Valencia de Fernando el Católico. Alfonso Sánchez, lugarteniente de tesorero general. Aragón en la Edad Media, 20, 709-721.

Spallanzani, M. (1997). Mercanti florentini nell'Asia Portoghese (1500-1525). Firenze: Edizioni SPES.

Sanchis Sivera, J. (ed). (2001). Dietari del capellá d'Anfós el Magnànim. València: Ajuntament de València. 
